\title{
Anti-diabetic effect of a preparation of vitamins, minerals and trace elements in diabetic rats: a gender difference
}

\author{
Márta Sárközy ${ }^{1}$, Veronika Fekete ${ }^{1}$, Gergő Szűcs ${ }^{1}$, Szilvia Török ${ }^{1}$, Csilla Szűcs $^{3}$, Judit Bárkányi ${ }^{3}$, Zoltán V Varga ${ }^{1,4}$, \\ Imre Földesi ${ }^{5}$, Csaba Csonka ${ }^{1,2}$, Csaba Kónya $^{3}$, Tamás Csont ${ }^{1,2+}$ and Péter Ferdinandy ${ }^{2,4^{*}+}$
}

\begin{abstract}
Background: Although multivitamin products are widely used as dietary supplements to maintain health or as special medical food in certain diseases, the effects of these products were not investigated in diabetes mellitus, a major cardiovascular risk factor. Therefore, here we investigated if a preparation of different minerals, vitamins, and trace elements (MVT) for human use affects the severity of experimental diabetes.

Methods: Two days old neonatal Wistar rats from both genders were injected with $100 \mathrm{mg} / \mathrm{kg}$ of streptozotocin or its vehicle to induce diabetes. At week 4, rats were fed with an MVT preparation or vehicle for 8 weeks. Well established diagnostic parameters of diabetes, i.e. fasting blood glucose and oral glucose tolerance test were performed at week 4, 8 and 12. Moreover, serum insulin and blood $\mathrm{HbA1 \textrm {c }}$ were measured at week 12.

Results: An impaired glucose tolerance has been found in streptozotocin-treated rats in both genders at week 4 . In males, fasting blood glucose and $\mathrm{HbA1c}$ were significantly increased and glucose tolerance and serum insulin was decreased at week 12 in the vehicle-treated diabetic group as compared to the vehicle-treated non-diabetic group. All of the diagnostic parameters of diabetes were significantly improved by MVT treatment in male rats. In females, streptozotocin treatment resulted in a less severe prediabetic-like phenotype as only glucose tolerance and $\mathrm{HbA} 1 \mathrm{c}$ were altered by the end of the study in the vehicle-treated diabetic group as compared to the vehicle-treated non-diabetic group. MVT treatment failed to improve the diagnostic parameters of diabetes in female streptozotocin-treated rats.

Conclusion: This is the first demonstration that MVT significantly attenuates the progression of diabetes in male rats with chronic experimental diabetes. Moreover, we have confirmed that females are less sensitive to STZ-induced diabetes and MVT preparation did not show protection against prediabetic state. This may suggest a gender difference in the pathogenesis of diabetes.
\end{abstract}

Keywords: Multivitamin, Minerals, Trace elements, Prevention, Streptozotocin, Diabetes, Gender difference

\section{Background}

The rapid increase in the prevalence of diabetes mellitus across the world gives diabetes the status of an epidemic in the 21st century [1]. In the last decades, there was an explosive increase in the number of people diagnosed with diabetes worldwide due to aging as well as increasing

\footnotetext{
*Correspondence: peter.ferdinandy@pharmahungary.com

${ }^{\dagger}$ Equal contributors

${ }^{2}$ Pharmahungary Group, Szeged, Hungary

${ }^{4}$ Department of Pharmacology and Pharmacotherapy, Faculty of Medicine,

Semmelweis University, Budapest, Hungary

Full list of author information is available at the end of the article
}

prevalence of obesity and physical inactivity [1-3]. The total number of people with diabetes is projected to rise from 347 million in 2008 [4] to 552 million in 2030 [5].

Not only total energy intake and macronutrients including carbohydrates, protein and fat, but also micronutrients including vitamins, minerals and trace elements have effects on the severity of diabetes mellitus. Clinical studies have shown that some individual vitamins e.g. A [6], B1 [7], B3 [8], C [9,10], D [11] and E [12], minerals e.g. calcium [13], magnesium [14] and trace elements e.g. zinc [15], chrome [16] beneficially affect the complications of 
diabetes mellitus. In these clinical studies, effects of individual vitamins, minerals and trace elements or combination of two or three components were investigated on diabetes. Surprisingly, there is no literature data available on the effects of multivitamin, minerals and trace elements containing preparations that can be used for human treatment in diabetes mellitus.

Regular consumption of vitamin/mineral supplements is common in developed countries [17] to maintain general health. In the United States, more than half of the adult population use dietary supplements $[18,19]$ primarily in the form of multivitamins with or without minerals [20]. In Germany, a study in 1998 reported that $18 \%$ of men and $25 \%$ of women were regular users of multivitamins in a sample of population aged 18-79 years [21]. Moreover, MVT preparations appeared on the market as medical food for diabetics; however, no literature data supports the beneficial effect of these preparations in preclinical or clinical studies.

Therefore, here we aimed to investigate if an MVT preparation containing 26 different minerals, vitamins and vitamin-like antioxidants, as well as trace elements affects the progression of diabetes in an experimental model of diabetes in rats.

\section{Methods}

This investigation conforms to the National Institutes of Health Guide for the Care and Use of Laboratory Animals (NIH Pub. No. 85-23, Revised 1996) and was approved by the Animal Research Ethics Committee of the University of Szeged.

Two days old neonatal male and female Wistar rats were used in this study. Lactating females with their litters were separately housed in individually ventilated cages (Sealsafe IVC system, Italy) and were maintained in a temperature-controlled room with a 12:12 h light: dark cycles for four weeks. After separation from the mother at week 4, littermates were housed in pairs under the same circumstances as mentioned above until 12 weeks of age. Standard rat chow (for ingredients see Additional file 1) and tap water were supplied ad libitum throughout the study.

\section{Experimental protocol}

Two day old neonatal male and female Wistar rats were injected with $100 \mathrm{mg} / \mathrm{kg}$ of streptozotocin $(\mathrm{STZ})(\mathrm{n}=69)$ or its vehicle (ice-cold citrate buffer) $(\mathrm{n}=38)$ to induce experimental diabetes mellitus (Figure 1). Neonatal rats were kept with the mother during the lactation period until week 4. For lactating mothers, standard rat chow and tap water were supplied ad libitum throughout the study. At week 4, fasting blood glucose measurement and an oral glucose tolerance test (OGTT) were performed in order to verify the development of impaired glucose tolerance of diabetes mellitus (Figure 1) in surviving animals. In the citrate buffer-treated group, 38 animals survived (mortality rate: $0 \%, \mathrm{n}=21$ male and 17 female). In the streptozotocin-treated group, 40 animals survived (mortality rate: $42 \%, \mathrm{n}=20$ males and 20 females). Both non-diabetic $(n=38)$ and diabetic rats $(n=40)$ were then fed per os via gavage $(1 \mathrm{~mL} / \mathrm{kg}, 1 \%$ methylcellulose suspension) with a MVT preparation $(253.3 \mathrm{mg} / \mathrm{kg} /$ day, suspended in methylcellulose) $(\mathrm{n}=9-10)$ to be registered as medical food for human use (Diacomplex film-coated tablet, Béres Pharmaceuticals, Budapest, Hungary; for content see Table 1$)$ or its vehicle $(157 \mathrm{mg} / \mathrm{kg} /$ day, suspended in methylcellulose) $(\mathrm{n}=8-11)$ for eight weeks (Figure 1). To conform to the human daily dose of the preparation, rat daily dose was adjusted according to the ratio of human and rat body surface areas. Fasting blood glucose measurement was performed in every second week and OGTT in every fourth week until week 12 to monitor the effect of multivitamin treatment on diabetes mellitus (Figure 1). Serum insulin and hemoglobinA1c level were measured at week 12 as well (Figure 1). To monitor the effect of diabetes mellitus on serum lipid levels, systemic inflammation, certain ion concentrations and activities of enzymes requiring vitamin cofactors, serum cholesterol, triglyceride, C-reactive protein (CRP), calcium, magnesium, phosphate and iron ion concentrations and LDH and ASAT enzyme activities were measured in the control placebo and diabetes placebo groups in both genders at week 12 .

\section{Blood glucose measurements and oral glucose tolerance test (OGTT)}

Rats were fasted overnight $(12 \mathrm{~h})$ prior to blood glucose level measurements (week 4, 6, 8, 10 and 12) and OGTTs (week 4, 8 and 12) in order to verify the development of diabetes mellitus and to monitor the effect of multivitamin treatment on diabetes. Blood samples were collected from the saphenous vein. Blood glucose levels were measured using Accucheck blood glucose monitoring systems (Roche Diagnostics Corporation, USA, Indianapolis) [22,23]. OGTT was performed as follows. After measurement of baseline glucose concentrations, glucose at $1.5 \mathrm{~g} / \mathrm{kg}$ body weight was administered via oral gavage and plasma glucose levels were measured 30, 60 and 120 minutes later and area under the curve was determined $[22,23]$.

\section{Hemoglobin A1c}

In order to monitor the chronic effect of MVT containing preparation on diabetes mellitus, hemoglobin A1c was measured from whole venous blood with an in vitro test (Bio-Rad in2it System) according to the instructions of the manufacturer. The test is based on single wave length photometry $(440 \mathrm{~nm})$ to detect glycated fraction separated from the non-glycated fraction by boronate affinity chromatography. 

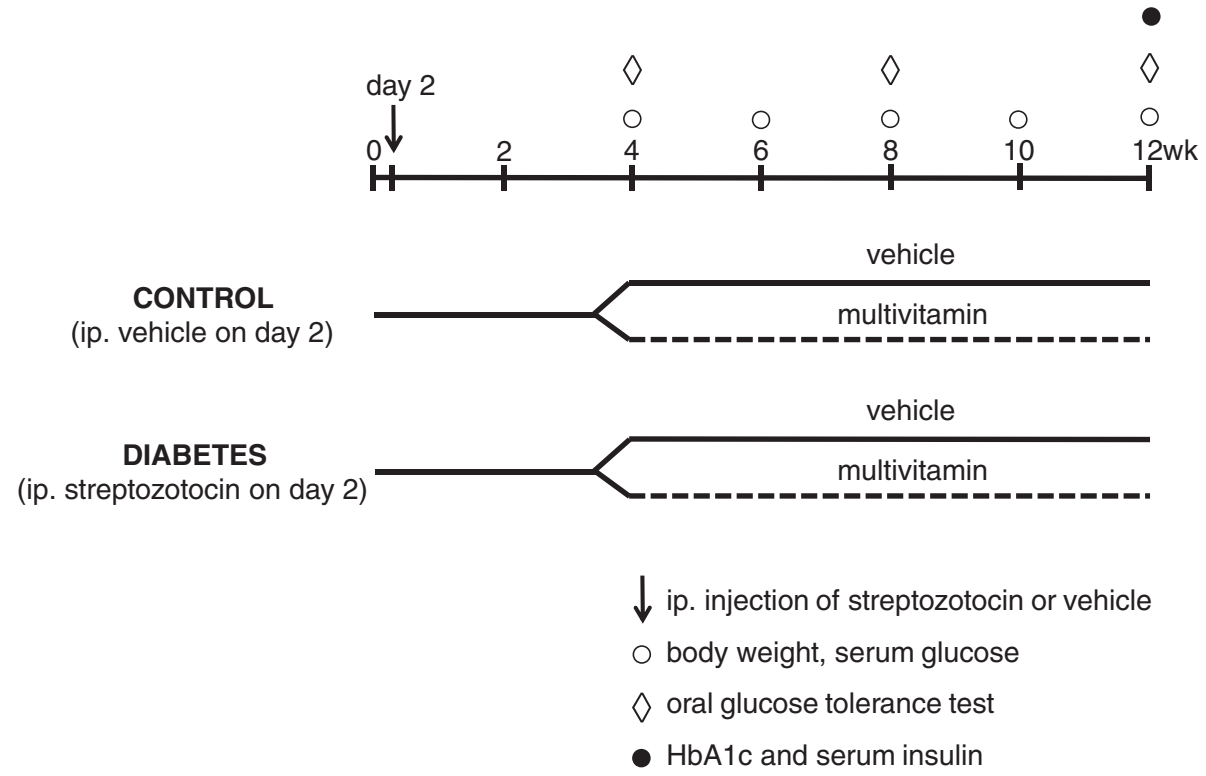

Figure 1 Experimental protocol. Two day old neonatal male and female Wistar rats were injected with $100 \mathrm{mg} / \mathrm{kg}$ of streptozotocin (STZ) $(n=69)$ or its vehicle $(n=38)$ to induce experimental diabetes mellitus. At week 4 , fasting blood glucose measurement and an oral glucose tolerance test (OGTT) were performed in order to verify the development of diabetes mellitus. Both non-diabetic $(n=38)$ and diabetic rats $(n=40)$ were then fed with a mixture of vitamins, minerals, and trace elements (MVT or vehicle for eight weeks). Fasting blood glucose measurement was performed in every second week and OGTT at week 4, 8 and 12 to monitor the effect of MVT treatment on diabetes mellitus. Serum insulin and hemoglobinA1c level were measured at week 12 as well.

\section{Measurement of serum insulin levels}

To monitor the effect of MVT treatment on diabetes mellitus, serum insulin levels were measured by an enzyme immunoassay (Mercodia, Ultrasensitive Rat Insulin ELISA) in duplicates according to the manufacturer's instructions as described [22].

Measurement of serum cholesterol and triglyceride levels Serum cholesterol and triglyceride levels were measured with test kits supplied by Diasys Diagnostic Systems (Holzheim, Germany) according to the instructions of the manufacturer.

\section{Measurement of serum CRP level as a systemic inflammatory marker}

Serum CRP level was determined with a commercially available immunturbidimetric kit from Roche Diagnostics (Mannheim, Germany) according to the instructions of the manufacturer.

\section{Measurement of serum ion concentrations}

Serum calcium, magnesium, phosphate and iron ion concentrations were measured with test kits from Roche Diagnostics (Mannheim, Germany) according to the instructions of the manufacturer.

\section{Measurement of serum enzyme activities}

Serum ASAT and LDH activities were measured in control placebo and diabetes placebo groups with kits from Roche Diagnostics (Mannheim, Germany) according to the instructions of the manufacturer.

\section{Statistical analysis}

Statistical analysis was performed by using Sigmaplot 12.0 for Windows (Systat Software Inc). All values are presented as mean \pm SEM. Two way repeated measures ANOVA was used to determine the effect of diabetes, MVT, and the interaction of these two factors on body weight, fasting blood glucose and glucose levels during oral glucose tolerance test in the entire population as well as in males or females, respectively. Two-Way ANOVA was used to determine the effect of diabetes, MVT, and the interaction of these two factors on glucose tolerance test AUC, HbA1c and blood glucose in the entire population as well as in males or females, respectively. After ANOVA, all pairwise multiple comparison procedures with Holm-Sidak post hoc tests were used as multiple range tests. In case of serum triglyceride, cholesterol and CRP levels, ion concentrations and enzyme activities, two sample t-tests were used to determine statistical significance between groups. $\mathrm{P} \leq 0.05$ was accepted as a statistically significant difference. 
Table 1 Ingredients of the MVT preparation

\begin{tabular}{|c|c|c|}
\hline Active ingredients & $\begin{array}{c}\text { Amount of ingredient/ } \\
1 \mathrm{~g} \text { product }\end{array}$ & Daily dose* \\
\hline Vitamin $A_{1}$ (Retinol) & 329 mg/g (1097 IU/g) & $\begin{array}{l}83.3 \mu \mathrm{\mu g} / \mathrm{kg} / \text { day } \\
(278 \mathrm{IU} / \mathrm{kg} / \text { day })\end{array}$ \\
\hline Vitamin $B_{1}$ (Thiamin) & $2.30 \mathrm{mg} / \mathrm{g}$ & $0.58 \mathrm{mg} / \mathrm{kg} / \mathrm{day}$ \\
\hline Vitamin $B_{2}$ (Riboflavin) & $2.63 \mathrm{mg} / \mathrm{g}$ & $0.67 \mathrm{mg} / \mathrm{kg} / \mathrm{day}$ \\
\hline Vitamin $B_{3}$ (Nicotinamide) & $11.8 \mathrm{mg} / \mathrm{g}$ & $2.99 \mathrm{mg} / \mathrm{kg} /$ day \\
\hline Vitamin $B_{5}$ (Pantothenic acid) & $3.95 \mathrm{mg} / \mathrm{g}$ & $1.00 \mathrm{mg} / \mathrm{kg} /$ day \\
\hline Vitamin $B_{6}$ (Pyridoxine) & $3.29 \mathrm{mg} / \mathrm{g}$ & $0.83 \mathrm{mg} / \mathrm{kg} /$ day \\
\hline Vitamin $B_{12}$ (Cyanocobalamin) & $3 \mu \mathrm{g} / \mathrm{g}$ & $0.76 \mu \mathrm{g} / \mathrm{kg} /$ day \\
\hline Folic acid & $197 \mu \mathrm{g} / \mathrm{g}$ & $49.9 \mu \mathrm{g} / \mathrm{kg} /$ day \\
\hline Biotin & $99 \mu \mathrm{g} / \mathrm{g}$ & $25.1 \mu \mathrm{g} / \mathrm{kg} /$ day \\
\hline Vitamin $D_{3}$ (Cholecalciferol) & $3 \mu \mathrm{g} / \mathrm{g}(120 \mathrm{IU} / \mathrm{g})$ & $\begin{array}{l}0.76 \mu \mathrm{g} / \mathrm{kg} / \text { day } \\
(30.4 \mathrm{UU} / \mathrm{kg} / \text { day })\end{array}$ \\
\hline Vitamin $\mathrm{K}_{1}$ (Phyllokinone) & $26 \mu \mathrm{g} / \mathrm{g}$ & $6.59 \mu \mathrm{g} / \mathrm{kg} / \mathrm{day}$ \\
\hline Rutoside & $3.29 \mathrm{mg} / \mathrm{g}$ & $0.83 \mathrm{mg} / \mathrm{kg} /$ day \\
\hline Vitamin C & $65.8 \mathrm{mg} / \mathrm{g}$ & $16.7 \mathrm{mg} / \mathrm{kg} / \mathrm{day}$ \\
\hline Vitamin E & $32.9 \mathrm{mg} / \mathrm{g}$ & $8.33 \mathrm{mg} / \mathrm{kg} /$ day \\
\hline Lutein & $1.97 \mathrm{mg} / \mathrm{g}$ & $0.50 \mathrm{mg} / \mathrm{kg} / \mathrm{day}$ \\
\hline Chrome & $39 \mu \mathrm{g} / \mathrm{g}$ & $9.88 \mu \mathrm{g} / \mathrm{kg} /$ day \\
\hline Zinc & 9.87 mg/g & $2.50 \mathrm{mg} / \mathrm{kg} / \mathrm{day}$ \\
\hline Selenium & $26 \mu \mathrm{g} / \mathrm{g}$ & $6.59 \mu \mathrm{g} / \mathrm{kg} /$ day \\
\hline Iron & $2.63 \mathrm{mg} / \mathrm{g}$ & $0.67 \mathrm{mg} / \mathrm{kg} /$ day \\
\hline lodine & $66 \mu \mathrm{g} / \mathrm{g}$ & $16.7 \mu \mathrm{g} / \mathrm{kg} / \mathrm{day}$ \\
\hline Manganese & $0.66 \mathrm{mg} / \mathrm{g}$ & $0.17 \mathrm{mg} / \mathrm{kg} / \mathrm{day}$ \\
\hline Copper & $921 \mu \mathrm{g} / \mathrm{g}$ & $233 \mu \mathrm{g} / \mathrm{kg} /$ day \\
\hline Molybdenum & $49 \mu \mathrm{g} / \mathrm{g}$ & $12.4 \mu \mathrm{g} / \mathrm{kg} / \mathrm{day}$ \\
\hline Magnesium & $65.8 \mathrm{mg} / \mathrm{g}$ & 16.7 mg/kg/day \\
\hline Calcium & $132 \mathrm{mg} / \mathrm{g}$ & 33.4 mg/kg/day \\
\hline Phosphorus & 102 mg/g & $25.8 \mathrm{mg} / \mathrm{kg} /$ day \\
\hline
\end{tabular}

*To conform to the human daily dose of the preparation, rat daily dose was adjusted according to the ratio of human and rat body surface areas.

\section{Results}

In order to verify the development of diabetes mellitus in the STZ-treated rats, concentrations of several plasma metabolites and body weight were measured at week 4 and during the treatment and follow-up period at week $6,8,10$ and 12 (Figure 1). In the entire population of experimental animals of mixed genders, STZ-treated rats showed lower body weight from week 8 to week 12, and significantly increased fasting blood glucose at week 10 and 12 (Figure 2). In STZ-treated group, blood glucose levels were significantly decreased by MVT treatment at week 10 and 12 (Figure 2). However, male STZ-treated rats showed a significant rise in fasting blood glucose level at week 10 and 12 and a marked decrease in body weight from week 6 to the end of the follow up period (Figure 3a and c) showing the development of diabetes

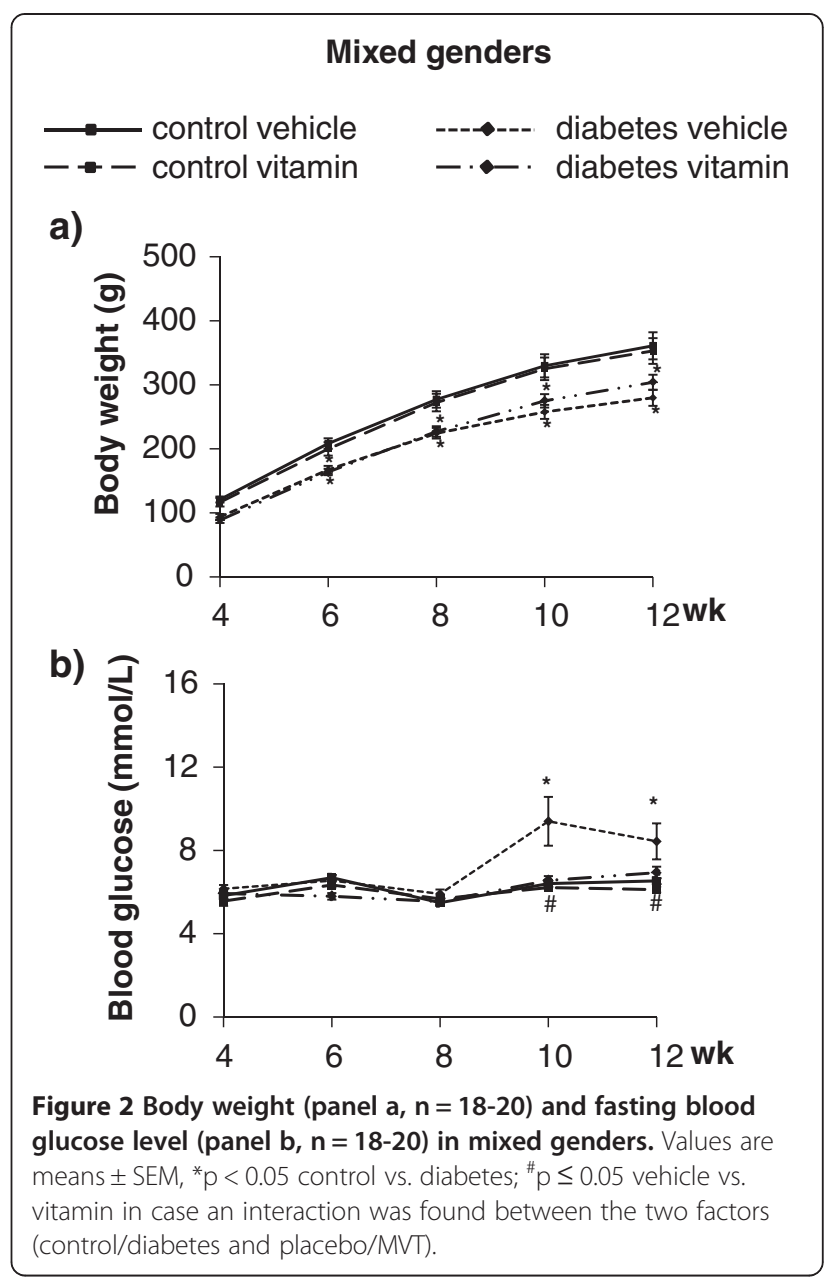

mellitus. Female STZ-treated rats failed to show elevated serum fasting glucose level and reduced body weight during the whole follow up period (Figure $3 \mathrm{~b}$ and d).

Oral glucose tolerance test showed increased area under the curve (AUC) in mixed genders, male and female in STZ-treated rats at week 4, 8 and 12 showing impaired glucose tolerance (Figures 4 and 5 and Table 2). MVT treatment showed significant decrease in OGTT AUC values at week 12 in case of mixed genders (Table 2). Separating the genders, multivitamin treatment decreased significantly the OGTT AUC only in male STZtreated rats at week 8 and 12 proving an anti-diabetic effect of multivitamin treatment (Table 2). However, MVT treatment did not change OGTT AUC in male control rats (Table 2). Interestingly, AUC remained unchanged by multivitamin treatment in female animals both in STZ-treated and control groups as well as at week 8 and 12 (Table 2).

HbA1c level was significantly higher in STZ-induced diabetes in mixed genders, as well as in males and females respectively as compared to controls (Figure 6) at week 12. Interestingly, multivitamin treatment has significantly 

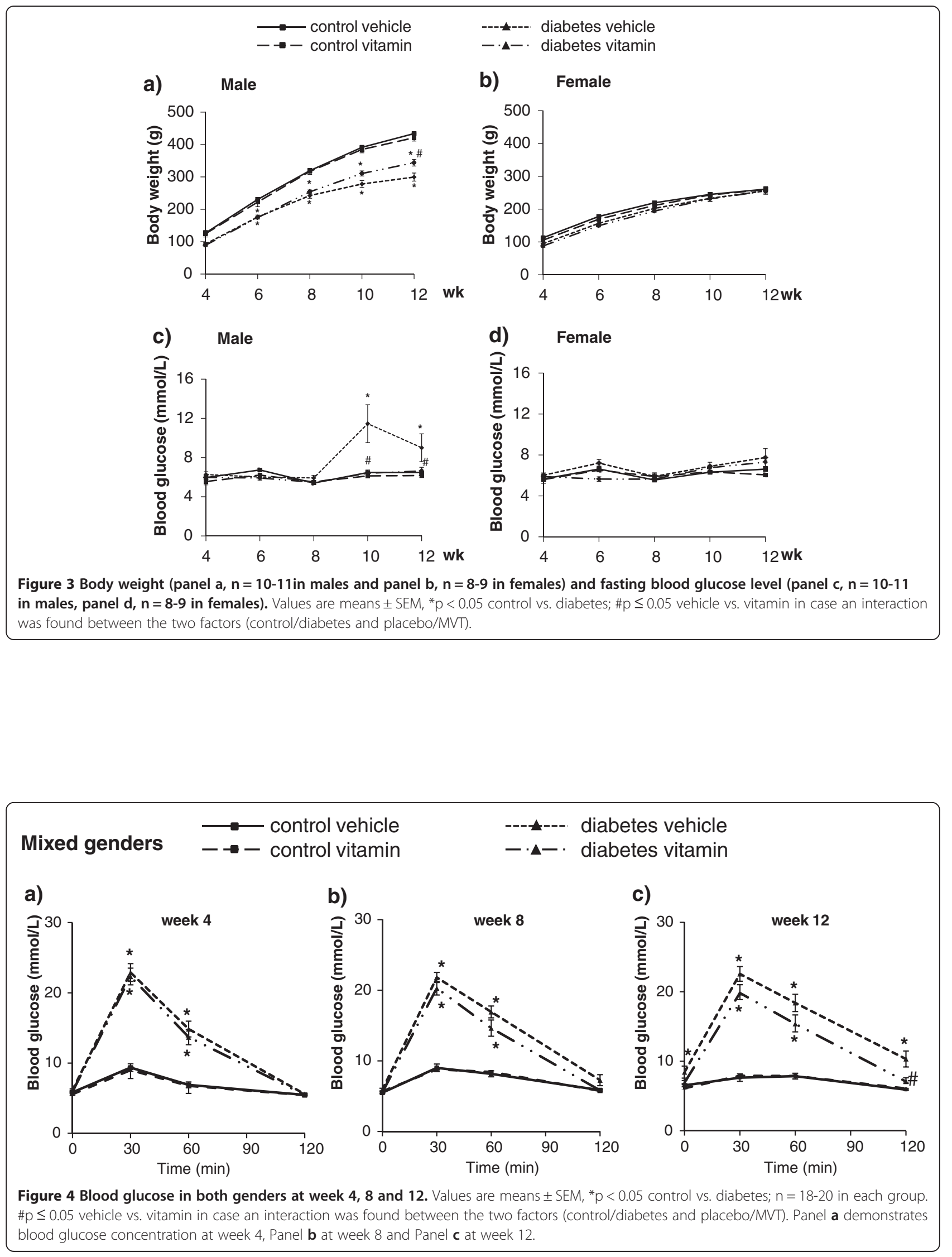


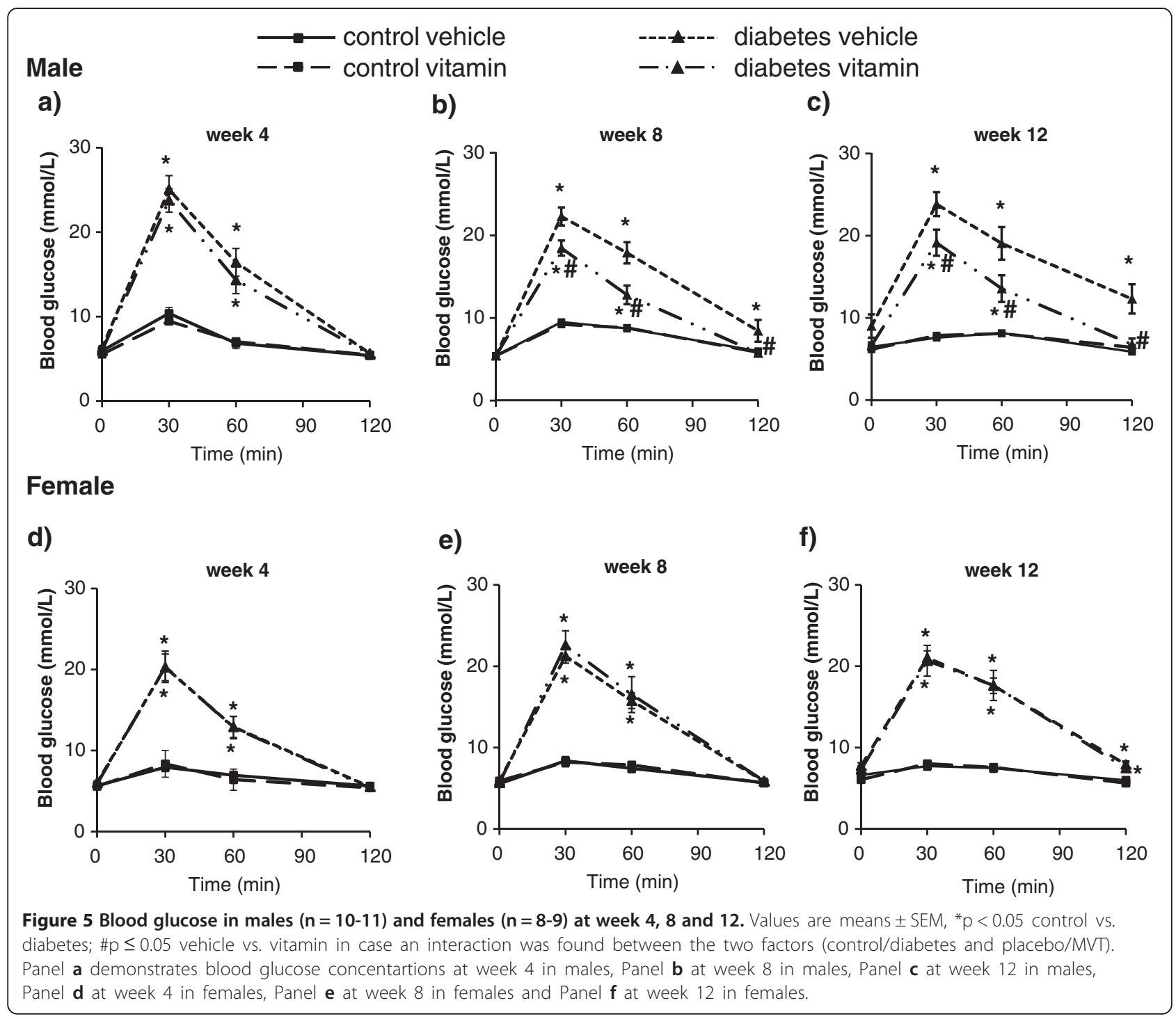

Table 2 OGTT AUC glucose values

\begin{tabular}{|c|c|c|c|c|c|c|}
\hline \multirow{2}{*}{$\begin{array}{l}\text { OGTT AUC glucose } \\
\text { (min*mmol/L) }\end{array}$} & \multicolumn{2}{|c|}{ Control } & \multicolumn{2}{|c|}{ Diabetes* } & \multirow[t]{2}{*}{ Week } & \multirow[t]{2}{*}{$\mathrm{n}$} \\
\hline & Vehicle & MVT & Vehicle & MVT & & \\
\hline Mixed genders & $818 \pm 22$ & $821 \pm 18$ & $1615 \pm 84$ & $1539 \pm 82$ & 4 & $18-20$ \\
\hline Mixed genders & $895 \pm 22$ & $900 \pm 21$ & $1723 \pm 76$ & $1480 \pm 86$ & 8 & $18-20$ \\
\hline Mixed genders & $858 \pm 13$ & $866 \pm 17$ & $1942 \pm 123$ & $1596 \pm 108^{\#}$ & 12 & $18-20$ \\
\hline Males & $829 \pm 24$ & $846 \pm 13$ & $1754 \pm 114$ & $1613 \pm 112$ & 4 & $10-11$ \\
\hline Males & $940 \pm 17$ & $932 \pm 24$ & $1816 \pm 126$ & $1384 \pm 74^{\#}$ & 8 & $10-11$ \\
\hline Males & $868 \pm 14$ & $884 \pm 25$ & $2076 \pm 195$ & $1486 \pm 130^{\#}$ & 12 & $10-11$ \\
\hline Females & $808 \pm 41$ & $785 \pm 37$ & $1444 \pm 102$ & $1437 \pm 118$ & 4 & $8-9$ \\
\hline Females & $839 \pm 38$ & $857 \pm 33$ & $1609 \pm 59$ & $1597 \pm 167$ & 8 & $8-9$ \\
\hline Females & $846 \pm 25$ & $841 \pm 12$ & $1776 \pm 75$ & $1746 \pm 181$ & 12 & $8-9$ \\
\hline
\end{tabular}

Two Way ANOVA, ${ }^{*} p<0.05$, Control vs. Diabetes including all groups in all time points, ${ }^{*} p \leq 0.05$ vehicle vs. vitamin in case an interaction was found between the two factors (control/diabetes and placebo/MVT). 


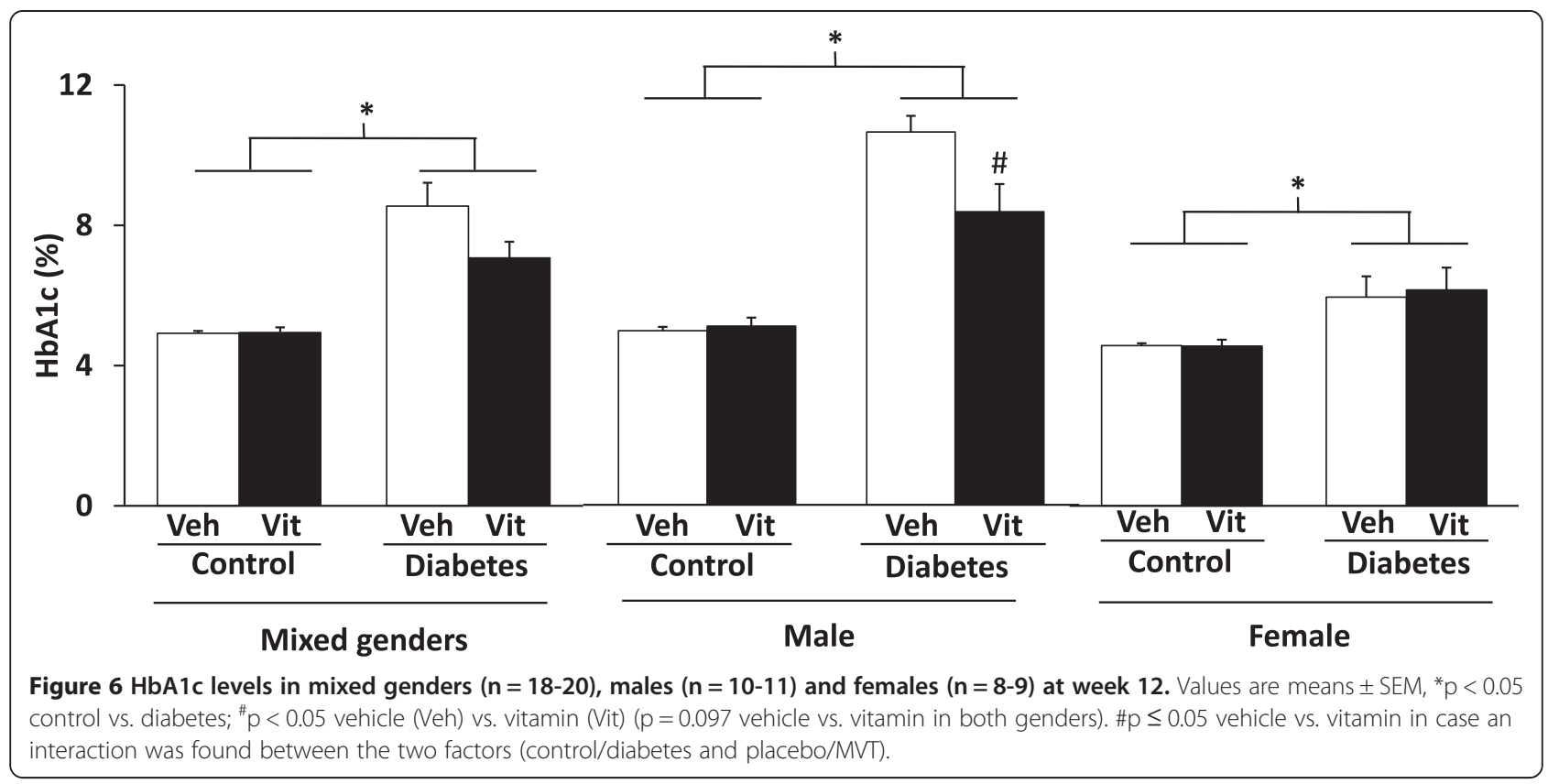

reduced HbA1c level only in STZ-treated males without having any effect in STZ-treated females and control animals in both genders (Figure 6).

Serum insulin concentration was significantly decreased in STZ-treated animals proving beta cell damage (Figure 7). MVT treatment showed a statistically not significant increasing tendency in STZ-treated animals (Figure 7). Separate evaluation of the data of the genders revealed that multivitamin treatment improved serum insulin level in STZ-treated males; however, serum insulin levels remained unaffected by the multivitamin treatment in control males (Figure 7). Neither diabetes mellitus, nor multivitamin treatment had a significant effect on serum insulin levels in female animals (Figure 7).

Serum triglyceride, cholesterol and CRP levels, ion concentrations including calcium, magnesium, phosphate and iron, and LDH and ASAT enzyme activities were not significantly altered in response to diabetes in either gender in our present study (Additional file 2) in contrast to some literature data $[24,25]$.

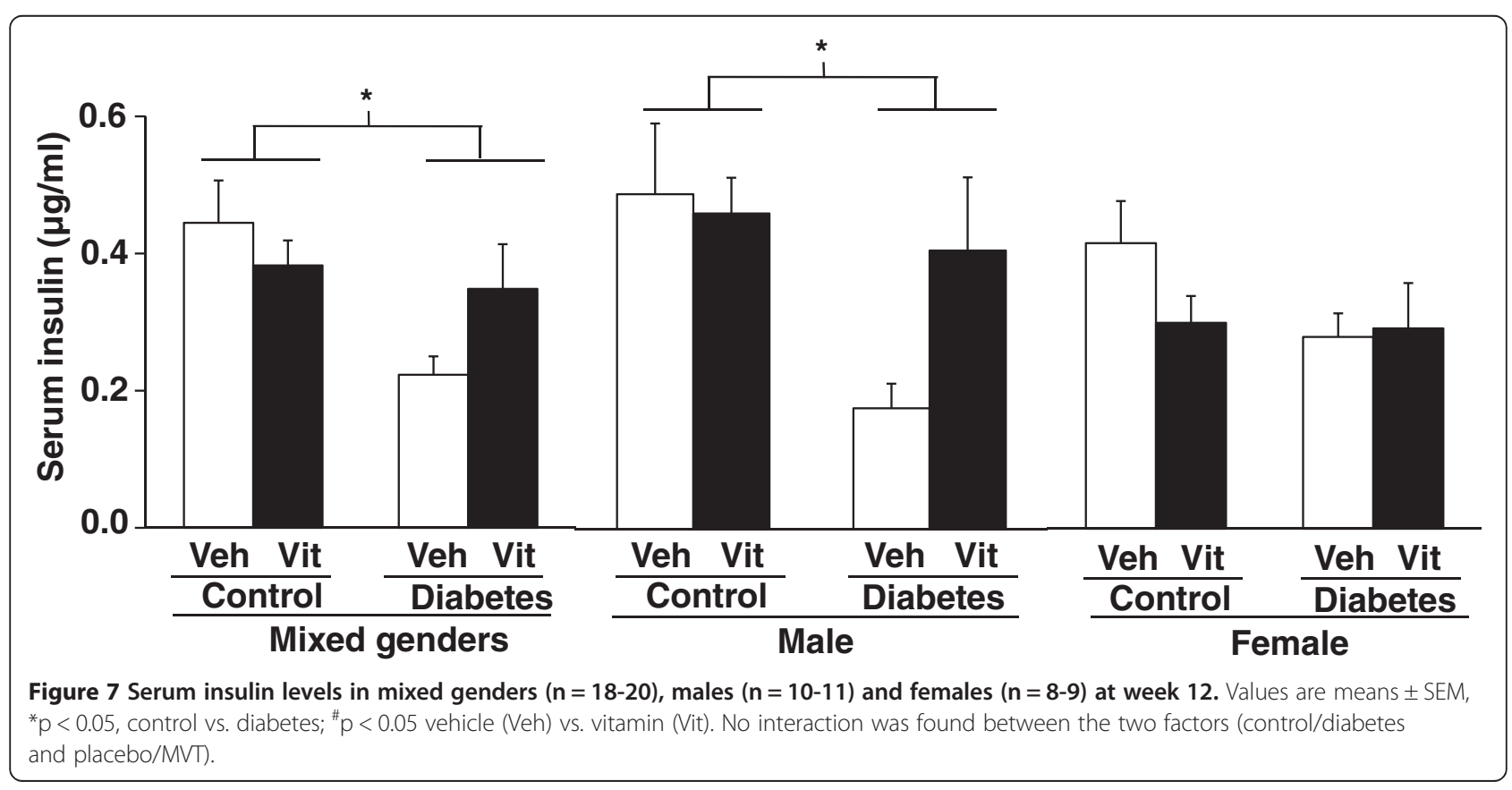




\section{Discussion}

Here we have shown that chronic treatment with an MVT preparation improved well established diagnostic markers of diabetes such as fasting blood glucose, HbA1c, glucose tolerance, and serum insulin levels in male diabetic rats. Furthermore, we have shown here that females developed a less severe prediabetic-like phenotype in response to neonatal STZ-treatment as only OGTT was impaired and HbA1c was increased. In the female animals, the MVT preparation failed to attenuate the progression of diabetes significantly. This is the first demonstration, that an MVT preparation attenuates the progression of experimental diabetes in males but not in females, which may suggest a gender difference in the pathogenesis of diabetes.

Regular consumption of MVT preparations as food supplements or medical food for diabetics is common in developed countries. However, surprisingly preclinical or clinical evaluation of such preparations is not available in the literature. Therefore, here we evaluated the effect of chronic treatment with an MVT preparation containing 15 vitamins and vitamin-like substances such as lutein and rutoside, 3 minerals, and 8 micro/trace elements in experimental diabetic rats. The MVT preparation showed beneficial effects on major markers of diabetes in male but not in female rats in the present study. This is the first evidence in the literature that a complex MVT preparation developed for human consumption significantly delayed progression of diabetes in an animal model. The reason why the MVT preparation was ineffective in female rats is not known, however, it should be emphasized that female rats developed only an impaired glucose tolerant state characterized by an increased OGTT AUC and HbA1c levels in the present study. It is well known that the progression of diabetes occurs at a later age and becomes milder in females compared to age-matched males in rodent models of diabetes (see for review [26]). One may speculate that this could be one of the reasons why the MVT preparation used in our present study was unable to improve the biochemical markers of early diabetes significantly.

In our present study, neonatal STZ treatment in rats resulted in a condition that was more similar to T1DM than to T2DM. However, it has been shown in the literature that neonatal rats injected with streptozotocin developed acute diabetes followed by a spontaneous remission due to some pancreatic $\beta$-cell regeneration. Therefore, there is no total insulin deficiency, but a decreased serum insulin concentration in STZ-treated animals [27-29]. Our present study is in accordance with these literature data, because serum insulin concentration was significantly lower in males and mixed genders in STZ-treated animals at week 12 (Figure 7). The literature is limited on the effect of different individual minerals and vitamins or related gender differences on pancreatic beta cell regeneration in diabetes. However, there are some well-known vitamins and minerals including vitamin B3 and $\mathrm{D}$ as well as calcium ion that have been previously linked to $\beta$-cell regeneration in diabetes. Vitamin B3 has been shown to stimulate $\beta$-cell regeneration in partially pancreatectomized rats [30,31], lengthen the "honeymoon" period in type 1 diabetic patients [30,32], and improve insulin secretion from patients at high risk of developing type 1 diabetes $[30,33]$. Nicotinamide also protects $\beta$-cells from streptozotocin-induced damage in rodents through a suggested mechanism involving inhibition of PARP [30,34-36]. Recently, vitamin D is thought to have beneficial effects on pancreatic beta-cell dysfunction possibly via both vitamin D receptor-dependent and -independent actions in diabetic patients of both genders [37]. In addition, $\mathrm{Ca}^{2+}$ depletion has been shown to decrease $\beta$-cell proliferation and increase $\beta$-cell death by apoptosis [38]. These studies, in agreement with our present findings, may suggest that the multivitamin preparation beneficially affects $\beta$-cell regeneration in male rats in our present study; however, this potential effect should be investigated in further studies.

In different experimental diabetes models and clinical studies involving limited number of patients, several data are available on the effect of individual vitamins, minerals, trace elements, or the combination of limited number of them. The individual components of the MVT preparation investigated in the present study were selected by the manufacturer on the basis of their preclinical and clinical data in different diabetic animal models or patient populations. Daily doses of all components of the preparation were set below the human upper safe level [39].

Effects of individual vitamins on diabetes and/or its complications have been investigated in a number of preclinical and clinical trials. It was demonstrated that a 2-week administration of vitamin B1 in a high dose $(0.2 \%$ thiamin in drinking water) prevents diabetes-induced cardiac fibrosis without reducing the blood glucose level in male diabetic rats [7]. A randomized double-blind vehiclecontrolled clinical pilot study recruiting 40 type 2 diabetics with microalbuminuria demonstrated that a high-dose vitamin B1 therapy (300 mg/day) for 3 months produced a regression of urinary albumin excretion without any effect on plasma glucose or HbA1c levels [40]. Vitamin D deficiency is a known risk factor of diabetes mellitus. A double-blind parallel group vehicle-controlled randomized trial involving 87 type 2 diabetics reported that a single large dose $(100,000 \mathrm{IU})$ of vitamin D2 improved endothelial function 8 weeks after the administration, however, HbA1c and HOMA-IS were unaffected by vitamin D2 therapy [41]. Additionally, another randomized, vehicle-controlled clinical trial with 81 participants showed that vitamin D3 supplementation (4000 IU) for 
6 months significantly improved insulin sensitivity and fasting insulin level in type 2 diabetic women [11].

A number of preclinical and clinical trials have investigated the effects of individual minerals on diabetes and/ or its complications. A randomized controlled, singleblinded trial with 31 patients demonstrated that oral calcium supplementation ( $1500 \mathrm{mg} /$ day) for 2 months improves insulin sensitivity in patients with type 2 diabetes and hypertension, however, both fasting blood glucose and HbA1c levels were unaffected by the calcium supplementation [42]. Furthermore, it was shown that dietary calcium supplementation $(600 \mathrm{mg} /$ day) for 3 months significantly reduced vascular resistance and induced partial regression of left ventricular hypertrophy in hypertensive non-insulindependent diabetic Afro-Americans [13]. A clinical randomized double-blind vehicle-controlled trial recruiting 63 type 2 diabetic patients with hypomagnesemia receiving glibenclamide has shown that supplementation of magnesium ( $2.5 \mathrm{~g} \mathrm{MgCl}_{2} /$ day) for 4 months improved $\mathrm{HbAlc}$, fasting glucose as well as insulin levels [43]. Another double-blind vehicle-controlled clinical trial enrolling 82 diabetic hypertensive adults with hypomagnesemia receiving captopril demonstrated that oral magnesium supplementation ( $2.5 \mathrm{~g} \mathrm{MgCl}_{2} /$ day) for 4 months significantly reduced fasting plasma glucose as well as $\mathrm{HbA1c}$ levels, systolic and diastolic blood pressure [14]. In contrast, a randomized clinical study involving 97 patients showed that chronic supplementation of magnesium ( $300 \mathrm{mg} /$ day) for 5 years attenuated the evolution of polyneuropathy in type 1 diabetics with magnesium deficiency without reducing HbA1c level [44].

Limited number of clinical data on some individual trace elements has shown beneficial effects on diabetes and its complications. A clinical pilot study involving 22 patients demonstrated that zinc supplementation $(30 \mathrm{mg} /$ day) for 3 months decreased lipid peroxidation in type 1 diabetes mellitus [45]. A prospective double-blind vehiclecontrolled crossover study involving 30 participants demonstrated that supplementation of chromium for 2 months significantly reduced serum triglyceride level in type 2 diabetic patients without any effect on serum glucose level [46]. In contrast, another randomized clinical study involving 180 patients with type 2 diabetes showed that chromium administration $(1000 \mu \mathrm{g} /$ day $)$ for 4 months had beneficial effects on HbA1c, glucose, insulin, and cholesterol variables [16].

Limited data on combinations of few numbers of vitamins, minerals and trace elements have shown beneficial effects on diabetes and/or its cardiovascular complications. A randomized, double-blind, vehicle-controlled clinical trial showed that a combination of $200 \mathrm{mg}$ magnesium, $30 \mathrm{mg}$ zinc, $200 \mathrm{mg}$ vitamin C, and $100 \mathrm{IU}$ vitamin E significantly improved glomerular function [6], blood pressure [47] and increased HDL-c and apo A1 level [47] without beneficially affecting serum glucose and HbA1c levels in 69 patients with type 2 diabetes mellitus after 3 months daily treatment. A randomized clinical trial enrolling 64 children with recent onset of type 1 diabetes (IMDIAB IX) demonstrated that implementation of insulin therapy with vitamin B3 (25 mg/kg body weight) alone or in combination with vitamin $\mathrm{E}$ ( $15 \mathrm{mg} / \mathrm{kg}$ body weight) for 2 years preserved baseline $C$-peptide secretion without any effect on HbA1c level [48]. In contrast, a vehiclecontrolled double-blind randomized clinical trial involving 348 participants has reported that statin therapy co-supplemented with biotin $(2 \mathrm{mg} /$ day $)$ and chromium $(600 \mu \mathrm{g} /$ day $)$ for 3 months has significantly decreased serum glucose, HbA1c, LDL-cholesterol, total cholesterol, and VLDL-cholesterol levels in type 2 diabetic patients [49]. In many of the abovementioned studies $[6,11,40,41,45,47,49]$, some of the individual vitamins, minerals and trace elements were used in a daily dose above the upper safe level [39]. A pilot clinical study in Sri Lanka involving 96 patients demonstrated that a 15component MVT preparation significantly reduced serum glucose and lipid levels in adult diabetic patients after 4 months of supplementation [36], however, the daily dose of 3 components of this preparation was above the upper safe level and no gender difference was investigated [50].

The limitation of the present study is that it does not provide evidence on the mechanism of the effect of the MVT preparation and the individual contribution of the 26 components to the anti-diabetic effect of the preparation. The potential interactions of these components and their combined effect rather than a single component could be responsible for the beneficial effects of the MVT preparation on the severity of diabetes. However, investigation of the effects of each components and their different variation of combinations was out of the scope of the present study.

\section{Conclusion}

Although MVT preparations are widely used by diabetics, our present study is the first demonstration that a MVT preparation attenuates the progression of experimental diabetes. Moreover, it seems that there is a gender difference in the development of diabetes and the anti-diabetic effect to MVT treatment. Further studies are needed to optimize the composition and to elucidate the efficacy, safety and the mechanism of the effect of MVT preparations in diabetics.

\section{Additional files}

Additional file 1: Ingredients of the standard rat chow.

Additional file 2: Effect of diabetes mellitus on serum triglyceride, cholesterol and CRP levels, calcium, magnesium, phosphate and iron concentrations, LDH and ASAT enzyme activities in both genders. 


\section{Competing interests}

Béres Pharmaceuticals Ltd., Pharmahungary Group and University of Szeged had a consortial grant funded by the National Development Agency (MED_FOOD TECH_08-A1-2008-0275) to develop MVT preparations for diabetic patients, Béres Pharmaceuticals Ltd. was the leader of this consortial project. C.S., J. B. and C. K. are employed by Béres Pharmaceuticals Ltd. P.F. is the owner and T.C. and C.C. are involved in the management of Pharmahungary Group, a pharmaceutical/biotechnological company.

\section{Authors' contributions}

CK, TC and PF conception and design of research; MS, VF, GS, TS, CS, JB, ZW and IF performed experiments; MS, VF, GS, TS, CS, JB and CC analysed data; MS, VF, GS, JB and TC interpreted results of experiments; MS prepared figures; MS, TC and PF drafted manuscript; MS, TC and PF edited and revised manuscript; MS, VF, GS, TS, CS, JB, ZW, IF, CC, CK, TC and PF approved final version of manuscript. All authors read and approved the final manuscript.

\section{Source of funding}

This work was supported by grants from the National Development Agency (MED FOOD TECH_08-A1-2008-0275, Baross DA-TECH-07-2008-0041, TÁMOP-4.2.1/B-09/1/KONV-2010-0005, TÁMOP-4.2.2/B-10/1-2010-0012, TÁMOP-4.2.2.A-11/1/KONV-2012-0035), the Hungarian Scientific Research Fund (OTKA K79167), and co-financed by the European Regional Development Fund and VÁTI Hungarian Nonprofit LLC for Regional Development and Town Planning (HURO/0901/137/2.2.2-HU-RO-TRANS-MED). The project was supported by the European Foundation for the Study of Diabetes New Horizons Collaborative Research Initiative. M. Sarkozy and G. Szucs hold a "Jedlik Ányos Predoctoral Fellowship". This research was realized in the frames of TÁMOP-4.2.4.A/2-11/1-2012-0001 National Excellence Program - Elaborating and operating an inland student and researcher personal support system. The project was subsidized by the European Union and co-financed by the European Social Fund. T. Csont held a "János Bolyai Felowship" of the Hungarian Academy of Sciences. We acknowledge the technical support of Judit Pipis for blood sampling and serum insulin measurements. P. Ferdinandy is a Szentágothai Fellow of the National Program of Excellence (TAMOP 4.2.4.A/2-11-1-2012-0001).

\section{Author details}

${ }^{1}$ Cardiovascular Research Group, Department of Biochemistry, Faculty of Medicine, University of Szeged, Szeged, Hungary. ${ }^{2}$ Pharmahungary Group, Szeged, Hungary. ${ }^{3}$ Béres Pharmaceuticals Ltd, Budapest, Hungary. ${ }^{4}$ Department of Pharmacology and Pharmacotherapy, Faculty of Medicine, Semmelweis University, Budapest, Hungary. ${ }^{5}$ Department of Laboratory Medicine, Faculty of Medicine, University of Szeged, Szeged, Hungary.

\section{Received: 24 May 2014 Accepted: 18 August 2014}

\section{Published: 26 August 2014}

\section{References}

1. Zimmet P, Alberti KG, Shaw J: Global and societal implications of the diabetes epidemic. Nature 2001, 414:782-787.

2. Wild $\mathrm{S}$, Roglic G, Green A, Sicree R, King H: Global prevalence of diabetes: estimates for the year 2000 and projections for 2030. Diabetes Care 2004, 27:1047-1053

3. Astrup A, Finer N: Redefining type 2 diabetes: 'diabesity' or 'obesity dependent diabetes mellitus'? Obes Rev 2000, 1:57-59.

4. Danaei G, Finucane MM, Lu Y, Singh GM, Cowan MJ, Paciorek CJ, Lin JK Farzadfar F, Khang YH, Stevens GA, Rao M, Ali MK, Riley LM, Robinson CA, Ezzati M: National, regional, and global trends in fasting plasma glucose and diabetes prevalence since 1980: systematic analysis of health examination surveys and epidemiological studies with 370 country-years and 2.7 million participants. Lancet 2011, 378:31-40.

5. Whiting DR, Guariguata L, Weil C, Shaw J: IDF diabetes atlas: global estimates of the prevalence of diabetes for 2011 and 2030. Diabetes Res Clin Pract 2011, 94:311-312.

6. Farvid MS, Siassi F, Jalali M, Hosseini M, Saadat N: Comparison of the effects of vitamins and/or mineral supplementation on glomerular and tubular dysfunction in type 2 diabetes. Diabetes Care 2005, 28:2458-2464.

7. Kohda Y, Shirakawa H, Yamane K, Otsuka K, Kono T, Terasaki F, Tanaka T: Prevention of incipient diabetic cardiomyopathy by high-dose thiamine. J Toxicol Sci 2008, 33:459-472.
8. Crinó A, Schiaffini R, Ciampalini P, Suraci MC, Manfrini S, Visalli N, Matteoli MC, Patera P, Buzzetti R, Guglielmi C, Spera S, Costanza F, Fioriti E, Pitocco D, Pozzilli P, IMDIAB Group: A two year observational study of nicotinamide and intensive insulin therapy in patients with recent onset type 1 diabetes mellitus. J Pediatr Endocrinol Metab 2005, 18:749-754

9. Chen H, Karne RJ, Hall G, Campia U, Panza JA, Cannon RO 3rd, Wang Y, Katz A, Levine M, Quon MJ: High-dose oral vitamin C partially replenishes vitamin $C$ levels in patients with Type 2 diabetes and low vitamin $C$ levels but does not improve endothelial dysfunction or insulin resistance. Am J Physiol Heart Circ Physiol 2006, 290:H137-H145.

10. Hirooka Y, Eshima K, Setoguchi S, Kishi T, Egashira K, Takeshita A: Vitamin C improves attenuated angiotensin II-induced endothelium-dependent vasodilation in human forearm vessels. Hypertens Res 2003, 26:953-959.

11. von Hurst PR, Stonehouse W, Coad J: Vitamin D supplementation reduces insulin resistance in South Asian women living in New Zealand who are insulin resistant and vitamin $D$ deficient - a randomised, vehiclecontrolled trial. Br J Nutr 2010, 103:549-555.

12. Upritchard JE, Sutherland WH, Mann JI: Effect of supplementation with tomato juice, vitamin $\mathrm{E}$, and vitamin $\mathrm{C}$ on $\mathrm{LDL}$ oxidation and products of inflammatory activity in type 2 diabetes. Diabetes Care 2000, 23:733-738.

13. Zemel MB, Zemel PC, Bryg RJ, Sowers JR: Dietary calcium induces regression of left ventricular hypertrophy in hypertensive non-insulindependent diabetic blacks. Am J Hypertens 1990, 3:458-463.

14. Guerrero-Romero F, Rodriguez-Moran M: The effect of lowering blood pressure by magnesium supplementation in diabetic hypertensive adults with low serum magnesium levels: a randomized, double-blind, vehicle-controlled clinical trial. J Hum Hypertens 2009, 23:245-251.

15. Blostein-Fujii A, DiSilvestro RA, Frid D, Katz C, Malarkey W: Short-term zinc supplementation in women with non-insulin-dependent diabetes mellitus: effects on plasma 5'-nucleotidase activities, insulin-like growth factor I concentrations, and lipoprotein oxidation rates in vitro. Am J Clin Nutr 1997, 66:639-642.

16. Anderson RA, Cheng N, Bryden NA, Polansky MM, Cheng N, Chi J, Feng J: Elevated intakes of supplemental chromium improve glucose and insulin variables in individuals with type 2 diabetes. Diabetes 1997, 46:1786-1791.

17. Li K, Kaaks R, Linseisen J, Rohrmann S: Vitamin/mineral supplementation and cancer, cardiovascular, and all-cause mortality in a German prospective cohort EPIC-Heidelberg. Eur J Nutr 2012, 51:407-413.

18. Bailey RL, Gahche JJ, Lentino CV, Dwyer JT, Engel JS, Thomas PR, Betz JM, Sempos CT, Picciano MF: Dietary supplement use in the United States, 2003-2006. J Nutr 2011, 141:261-266.

19. Bailey RL, Fulgoni VL, Keast DR, Dwyer JT: Examination of vitamin intakes among US adults by dietary supplement use. J Acad Nutr Diet 2012, 112:657-663.

20. Radimer K, Bindewald B, Hughes J, Ervin B, Swanson C, Picciano MF: Dietary supplement use by US adults: data from the National Health and Nutrition Examination Survey, 1999-2000. Am J Epidemiol 2004, 160:339-344.

21. Beitz R, Mensink GB, Fischer B, Thamm M: Vitamins-dietary intake and intake from dietary supplements in Germany. Eur J Clin Nutr 2002, 56:539-545.

22. Sárközy M, Zvara A, Gyémánt N, Fekete V, Kocsis GF, Pipis J, Szücs G, Csonka C, Puskás LG, Ferdinandy P, Csont T: Metabolic syndrome influences cardiac gene expression pattern at the transcript level in male ZDF rats. Cardiovasc Diabetol 2013, 12:16.

23. Kocsis GF, Sárközy M, Bencsik P, Pipicz M, Varga ZV, Pálóczi J, Csonka C, Ferdinandy $P$, Csont T: Preconditioning protects the heart in a prolonged uremic condition. Am J Physiol Heart Circ Physiol 2012, 303:H1229-H1236.

24. Akiyama S, Katsumata S-i, Suzuki K, Ishimi Y, Jian W, Uehara M: Dietary Hesperidin Exerts Hypoglycemic and Hypolipidemic Effects in Streptozotocin-Induced Marginal Type 1 Diabetic Rats. J Clin Biochem Nutr 2010, 46:87-92.

25. Wang L, Duan G, Lu Y, Pang S, Huang X, Jiang Q, Dang N: The effect of Simvastatin on glucose Homeostasis in Streptozotocin induced type 2 diabetic rats. J Diabetes Res 2013, 2013:274986.

26. Franconi F, Seghieri G, Canu S, Straface E, Campesi I, Malorni W: Are the available experimental models of type 2 diabetes appropriate for a gender perspective? Pharmacol Res 2008, 57:6-18.

27. Portha B, Kergoat M: Dynamics of glucose-induced insulin release during the spontaneous remission of streptozocin diabetes induced in the newborn rat. Diabetes 1985, 34:574-579. 
28. Bonner-Weir S, Trent DF, Zmachinski CJ, Clore ET, Weir GC: Limited B cell regeneration in a $\mathrm{B}$ cell deficient rat model: studies with dexamethasone. Metabolism 1981, 30:914-918.

29. Liang XD, Guo YY, Sun M, Ding Y, Wang N, Yuan L, De W: Streptozotocininduced expression of Ngn3 and Pax4 in neonatal rat pancreatic a-cells. World J Gastroenterol 2011, 17:2812-2820.

30. Ye DZ, Tai MH, Linning KD, Szabo C, Olson LK: MafA expression and insulin promoter activity are induced by nicotinamide and related compounds in INS-1 pancreatic beta-cells. Diabetes 2006, 55:742-750.

31. Yonemura Y, Takashima T, Miwa K, Miyazaki I, Yamamoto H, Okamoto $\mathrm{H}$ : Amelioration of diabetes mellitus in partially depancreatized rats by poly (ADP-ribose) synthetase inhibitors: evidence of islet B-cell regeneration. Diabetes 1984, 33:401-404.

32. Vague $P$, Vialettes $B$, Lassman-Vague $V$, Vallo J: Nicotinamide may extend remission phase in insulin-dependent diabetes. Lancet 1987, 1:619-620.

33. Manna R, Migliore A, Martin LS, Ferrara E, Ponte E, Marietti G, Scuderi F, Cristiano G, Ghirlanda G, Gambassi G: Nicotinamide treatment in subjects at high risk of developing IDDM improves insulin secretion. $\mathrm{Br} J$ Clin Pract 1992, 46:177-179.

34. Burkart V, Wang ZQ, Radons J, Heller B, Herceg Z, Stingl L, Wagner EF, Kolb H: Mice lacking the poly(ADP-ribose) polymerase gene are resistant to pancreatic beta-cell destruction and diabetes development induced by streptozocin. Nat Med 1999, 5:314-319.

35. Masiello P, Broca C, Gross R, Roye M, Manteghetti M, Hillaaire-Buys D, Novelli M, Ribes G: Experimental NIDDM: development of a new model in adult rats administered streptozotocin and nicotinamide. Diabetes 1998, 47:224-229.

36. Kishore A, Nampurath GK, Mathew SP, Zachariah RT, Potu BK, Rao MS, Valiathan M, Chamallamudi MR: Antidiabetic effect through islet cell protection in streptozotocin diabetes: a preliminary assessment of two thiazolidin-4-ones in Swiss albino mice. Chem Biol Interact 2009, 177:242-246.

37. Pittas AG, Dawson-Hughes BJ: Vitamin D and diabetes. Steroid Biochem Mol Biol 2010, 121:425-429.

38. Herchuelz A, Nguidjoe $E$, Jiang $L$, Pachera N: $\beta$-Cell preservation and regeneration in diabetes by modulation of $\beta$-cell $\mathrm{Ca}^{2+}$ homeostasis. Diabetes Obes Metab 2012, 14(3):136-142.

39. European Commission Health and Consumer Protection DirectorateGeneral, Directorate E - Safety of the food chain: Orientation paper on the setting of maximum and minimum amounts for vitamins and minerals in foodstuffs. E4 - Food law, nutrition and labelling 2007. http://www.liberterre. fr/liberterres/codex/z-pdf-codex/ec_paper_july2007.pdf.

40. Rabbani N, Alam SS, Riaz S, Larkin JR, Akhtar MW, Shafi T, Thornalley PJ: High-dose thiamine therapy for patients with type 2 diabetes and microalbuminuria: a randomised, double-blind vehicle-controlled pilot study. Diabetologia 2009, 52:208-212.

41. Sugden JA, Davies JI, Witham MD, Morris AD, Struthers AD: Vitamin D improves endothelial function in patients with Type 2 diabetes mellitus and low vitamin D levels. Diabet Med 2008, 25:320-325.

42. Pikilidou MI, Lasaridis AN, Sarafidis PA, Befani CD, Koliakos GG, Tziolas IM, Kazakos KA, Yovos JG, Nilsson PM: Insulin sensitivity increase after calcium supplementation and change in intraplatelet calcium and sodium-hydrogen exchange in hypertensive patients with Type 2 diabetes. Diabet Med 2009, 26:211-219.

43. Rodriguez-Moran M, Guerrero-Romero F: Oral magnesium supplementation improves insulin sensitivity and metabolic control in type 2 diabetic subjects: a randomized double-blind controlled trial. Diabetes Care 2003, 26:1147-1152.

44. De Leeuw I, Engelen W, De Block C, Van Gaal L: Long term magnesium supplementation influences favourably the natural evolution of neuropathy in Mg-depleted type 1 diabetic patients T1dm. Magnes Res 2004, 17:109-114.

45. Faure P, Benhamou PY, Perard A, Halimi S, Roussel AM: Lipid peroxidation in insulin-dependent diabetic patients with early retina degenerative lesions: effects of an oral zinc supplementation. Eur J Clin Nutr 1995, 49:282-288

46. Lee NA, Reasner CA: Beneficial effect of chromium supplementation on serum triglyceride levels in NIDDM. Diabetes Care 1994, 17:1449-1452.

47. Farvid MS, Jalali M, Siassi F, Saadat N, Hosseini M: The impact of vitamin and/or mineral supplementation on lipid profiles in type 2 diabetes. Diabetes Res Clin Pract 2004, 65:21-28.
48. Crinò A, Schiaffini R, Manfrini S, Mesturino C, Visalli N, Beretta Anguissola G, Suraci C, Pitocco D, Spera S, Corbi S, Matteoli MC, Patera IP, Manca Bitti ML, Bizzarri C, Pozzilli P, IMDIAB group: A randomized trial of nicotinamide and vitamin $E$ in children with recent onset type 1 diabetes IMDIAB IX. Eur J Endocrinol 2004, 150:719-724.

49. Albarracin C, Fuqua B, Geohas J, Juturu V, Finch MR, Komorowski JR: Combination of chromium and biotin improves coronary risk factors in hypercholesterolemic type 2 diabetes mellitus: a vehicle-controlled, double-blind randomized clinical trial. J Cardiometab Syndr 2007, 2:91-97.

50. Gunasekara P, Hettiarachchi M, Liyanage C, Lekamwasam S: Effects of zinc and multimineral vitamin supplementation on glycemic and lipid control in adult diabetes. Diabetes Metab Syndr Obes 2011, 4:53-60.

doi:10.1186/1472-6823-14-72

Cite this article as: Sárközy et al:: Anti-diabetic effect of a preparation of vitamins, minerals and trace elements in diabetic rats: a gender difference. BMC Endocrine Disorders 2014 14:72.

\section{Submit your next manuscript to BioMed Central and take full advantage of:}

- Convenient online submission

- Thorough peer review

- No space constraints or color figure charges

- Immediate publication on acceptance

- Inclusion in PubMed, CAS, Scopus and Google Scholar

- Research which is freely available for redistribution 